\title{
The protection of historical landscape element in the city landscape renovation in principle
}

\author{
Haijun Lv \\ Institute of art and design, Huanghe Science and Technology College, Zhengzhou, China, 450063 \\ lhjhhkj@163.com
}

\begin{abstract}
KEYWORDS: Landscape, Transformation of the landscape, Element protection
ABSTRACT. Modern city landscape environment construction, unified in respect history, respect for life and need more historical landscape connotation and contemporary science and technology civilization. In the modern city construction tide in the city, the historical memory may be transient, city and so become dull. If the protection of the landscape elements of the original suitable down, will become the emotional regression places, and landscape elements of the original place becomes the object of protection and development of the new design of the. In addition, people not only to repeat the history and the history repeat itself, and protection for protection, and to stand in the angle of the history and development, re recognize the city historic landscape element protection value, explore the historical landscape elements of the new protection method and principle.
\end{abstract}

\section{Introduction}

We will issue the praise of ancient art, architecture, we study the events of the past, than the people of that time showed more interest in. For ordinary people, has a profound traditional atmosphere of historic landscape, is still able to arouse their inner sense of history, to experience the psychological, physiological status is different with the daily life. For example, see the familiar house, environment, nature will affect some childhood memories of the scene, with is that full of tender feelings of emotional memories.

\section{The principle of ecology}

The city is a "human on the natural environment adaptation, processing, transformation and the building up of the special artificial ecosystem", or "a natural, economic and social complex artificial ecological system". Reasonable utilization of existing landscape in the city landscape renovation, to avoid simply the pursuit of great momentum and heroism, to suit one's measures to local conditions, the original landscape elements to use.

In the natural landscape elements, nature to give every person or group of people, each city provides an adaptation of the special environment of growth -- the ecological environment, so each city's shape, interface, base of ups and downs, original vegetation and rivers, says Mr Lynch, are part of city image, city context, reflects the harmony between man and nature of ecological beauty. For a city, is to find the advantage. For example, the natural distribution of the city green space have a disorder of the United States, and landscape ecology emphasizes diversity of patch diversity, landscape type diversity and pattern, reasonable distribution of emphasizing the ecological plaque, emphasize the city ecological texture, so as long as we can to respect it in design, proper transformation, completely can create full of ecological beauty of city landscape. We know that both classical gardens or the modern landscape design, its source of inspiration were derived from natural. Only in the design of more natural, on the ecological environment to be concerned about, we design has inexhaustible vitality, will lead a healthy development road.

Also use ecology for the protection of the cultural landscape elements. For example, in twentieth Century after seventy years with the change from industrial era to the post industrial era, the emergence of a large number of industrial waste gas. Ecological landscape design methods used for modification of this kind of landscape, is to preserve the original elements and on the site of the original material reuse, and since twentieth Century seventy's has been the subject of foreign designers favor.

The landscape architect in the design to follow ecological protection in principle, follow the law of life, such as the reflection of regional biological, conform to the base of the natural conditions, 
reasonable use of soil, vegetation and other natural resources; use of local materials, especially pay attention to the use of native plants; emphasis on material recycling use and the use of waste material, in order to to reduce energy consumption, reduce maintenance cost; pay attention to the establishment of ecological system protection, biodiversity; play the role of natural ecological system itself, the establishment and development of a benign cycle; the natural elements and natural process, reduce the artificial marks.

\section{Local principle}

To respect the local characteristics, the outstanding natural and native characteristic. The specific process of urban landscape are the nature and culture, the two affect each other, common development, constitute the landscape characteristics and local spirit, in the urban landscape renovation should fully respect their local spirit, highlighting its own historical and cultural customs characteristics. Their approach is to historic landscape element has the characteristics of local protection, this is an important way to ensure the urban landscape diversity. Regional landscape design in urban centered, local culture, historical style should be protected fully and reflect, it is to solve one of the important channel of the city local cultural style lost, lost, such as the protection of landscape construction of Zhouzhuang, Pingyao County, Old Town of Lijiang is an example of success. As Mike Haag said: "when the city built in the beautiful, fascinating or resource rich places, often due to characteristics of the site taken to protect, develop and improve rather than on the site be obliterated the talent, the only way to form a outstanding city". Only in-depth understanding of the characteristics of the site, and from a more macro perspective to analyze problems, solve problems more comprehensive approach, may make the city sustainable development really.

\section{Cultural principle}

For culture, inherit the tradition, the continuation of history, is an inevitable phenomenon. Culture and art is the gradual development, it is more inclusive, in the development process from time to time to review traditional and before, so now we can read the three hundred Tang poems, read the book of songs. The city and the landscape is precisely the comprehensive cultural art and science and technology, so the protection of historic landscape, is for this culture continues to be know.

The original landscape remains as a special cultural resources in conserving and utilizing of landscape design, its meaning is firstly it contains certain social historical period values and ideals, and will inevitably continue carrying later historical values, therefore, the information accumulation is a changing dynamic, process. Based on this view, landscape planning and design should make full use of the original site resources, its development and utilization of monuments and landscape organically, reflects the historical and cultural heritage places, and to raise awareness of public participation in historical and cultural landscape heritage.

\section{The overall coordination principle}

Integrity means that each element through its relationship in each element in the position and surrounding elements embodied in. Landscape diversity, but diversity does not represent the disorder and complexity, diversity of integrity based on. The original landscape designers and builders of different, different nationalities, hobbies, cultural recreation and historical background, it will form a unique style of extraordinary splendour colorful. Despite their different characteristics, and if the surrounding environment of overall coordination, each other mutual echo, to maintain a certain degree of understanding, are worthy of research and protection. The landscape of the old and new design is not contradictory, but it is precisely the complementary.

Traditional landscape features should become a source of inspiration for the contemporary landscape design style innovation. Not to design the new landscape elements in the original place to take into account is not complete, lack of continuity, lack of familiarity. So the elements of landscape protection is not limited to the protection of individual elements, to protect the element is regarded as an element of the landscape in the framework of the connotation, and given it a complicated and in many aspects, such as history, psychology, life, are generated to ensure that 
made protection design efforts most works after energy and the environment. The coordination of them.

Landscape design to show the new needs of today's society. In the city landscape construction, and constantly inject time factor, continue to keep the city landscape characteristic. The traditional local characteristics of the landscape, is the result of the terrain, climate and building technology, folk customs, history and culture and other factors, it is inevitable with the development of the times, technology has its own evolution of the update process. So we should deepen the understanding of the traditional landscape culture, but also to strengthen the understanding of modern landscape culture. "The space of cross point to be formed in the three contemporary scientific culture, traditional culture and environment of the times review of national culture, regional culture, learn from foreign culture, continue to seek a full range of cultural identity, and to reverse the traditional, choose the traditional", striving to achieve the integration of national characteristics and modern, coexistence place and the sense of the times, the unity of tradition and innovation, in compatibility, coordination, fusion, regeneration in continuous evolution of contemporary local landscape culture. This takes place in the traditional style is based the new landscape and old landscape coordination, also affirmed the characteristics of their own age, let a person feel the landscape is new, is also the traditional.

Landscape design new inheritance history landscape value in the protection, also plays a more and more important role. Cherish the traditional value, development is not to ignore the progress of science and technology in the society, blindly imitate the past. The best imitation can only produce a fake, not genuine. Good design is not shallow on traditional imitation, but the long local garden tradition and modern life needs and aesthetic value very well together, and on this basis to improve the work of refining. From this point on the landscape of outstanding works of contemporary countries can deeply realize. These works, no matter how the modern form, we a little taste, are not difficult to find the traditional information they transfer. So in the process of transforming the old city, landscape, especially building not only do similar images, but should be "space, environment, technology and concepts as coordination media, analyze the history, further understanding of history, to re find the factors of disharmony between the media dialogue". Traditional landscape elements of the new landscape forms and absorption, with traditional features in common, they get together to show an eternal vitality of historical landscape.

So the city landscape planning and design of well to obtain the same era of diversity and unity of the equilibrium, so that the city can coordinate symbiosis, organic growth. That is to say, the real protection is not to reproduce the old style has been lost, but to retain the good now environment, and points out the possible future development direction. To avoid the attractive and can continue to use the living places suffer inappropriate changes even damage.

\section{Principle of environmental psychology}

City space is always changing constantly filled with new contents. Some originally is the edge of the place may become a center, originally is the center place now may be the original edge, some new landscape became old landscape, city development as a witness and we always find that here is some was removed, and then there were some built. If the two possibility there is a design scheme, one is to save the old landscape elements, use these to build; the second is to push the new flat field, besides Protect the Cultural Relics provisions of the state and local government, most of the landscape designers will choose the latter. This is the old landscape fate, this is no surprise, the original landscape elements protection is undoubtedly increases the difficulty of the design, it limits the designer's thinking, restricted site planning etc..

Human is symbolic animal, landscape is a symbol of communication media, is meaningful, it records the history of a place, including natural and social history; tells a moving story, including the beautiful or sad story; about land ownership, also tell people and land, the human and the human, and the relationship of man and society. Change brings new facilities can give people some sense of shock, but there are a lot of people with this place long association. And unique feeling, old landscape has a sense of history, familiar feeling deeply captured these people.

Not only to meet the functional requirements, but also to save some of the old landscape elements to meet people's psychological sense of familiarity, feeling. The old landscape in the longterm history, the formation of a rich environment affection. The landscape elements not only one 
kind of substance, it is the record of history, is a microcosm of civilization, is the spirit of the people to rely on, or are people living witness. Historical traces of the symbol of the city of the past, describing the city's story, they are worthy of our treasure and memory, the transformation in the landscape in the city to grasp these environmental emotion is the transformation of the key.

\section{Summary}

Each period of the city civilization, reflects the distinctive characteristics of the times. In other words, at any time to create a city landscape environment, will reflect the period of science and technology development level and the era of aesthetic consciousness. Modern city construction in the spring tide of historical memory, transient, if the protection of the landscape elements of the original suitable down, will be the people feelings return place, the original landscape element becomes the object of protection and development of the new design.

\section{References}

[1] Zhao Zhirong. Historic preservation values -- the pursuit of resource, environment and benefit (J) sustainable. City planning forum, 1999.

[2] Wang Xiangrong, Lin Qing. The value orientation of modern garden (J). China garden, 2003.

[3] Dai Tianxing. The city environmental ecology (M). Beijing: China Building Industry Press, 2002.

[4] Xu Lei green, Yang Gongxia. Environmental Psychology (M). Shanghai: Tongji University press, 2002. 